\title{
The Impact of Article 17 - A Study into its Effects on the Music Industry's Innovation Processes
}

Research Article

\author{
Frederik Juul Jensen* \\ Independent scholar and Artist Manager, Copenhagen, Denmark
}

Received December 30, 2020; Accepted December 16, 2021

Abstract: The recent adoption of article 17 in the EU's new Directive on Copyright in the Digital Single Market has led to much debate. Proponents believe it will facilitate fair and balanced competition, while opponents fear increased censorship and surveillance on the Internet. Based on comprehensive document analysis, the paper explores the relationship between regulation and innovation. Through a study into article 17's implementation in Denmark, this paper investigates how article 17 will affect the innovation processes in the European music industry. The paper argues that although article 17 strengthens the rightsholders' negotiation position, it does not decrease its dependence on the external IT Sector and its innovations.

Keywords: digitalisation • music industry • innovation • EU • regulation • sociotechnology

\section{Introduction}

The millennium shift marked a significant change in the consumption of music. In the 1990s, the music industry's earnings were at their all-time highest because of the popularity of the CD medium (Wikström \& DeFillippi 2016). However, with the IT sector's entry into the market, the music industry experienced multiple disruptions, which have weakened the rightsholders' negotiation power in the market. User-generated content platforms have challenged the industry's existing business models, and the rightsholders argue that the platforms are exploiting the $2001 \mathrm{EU}$ E-Commerce Directive's hosting exemption, also known as the 'safe harbour' rule. The hosting exemption allows platforms to avoid liability from user-uploaded content as long as they are unaware of the illegal content. The rightsholders argue that there exists a 'Value Gap', where platforms derive unreasonable value from providing users with the possibility to upload and access copyright-protected works without obtaining prior permission or license from the underlying rightsholders (Goossens 2019).

On 26 March 2019, the European Parliament approved the new Directive on Copyright in the Digital Single Market. The section containing article 17, known as article 13 in previous drafts, has proved highly controversial. Article 17 intends to improve the rightsholders' position in the digital market by making the digital platforms liable for the user-uploaded content. The directive, along with article 17, has to be implemented into national legislation within June 2021. The Danish rightsholder organisations look forward to having article 17 introduced in Danish law. They believe it creates fair competition between digital music providers, such as Spotify and YouTube, for the benefit of a sustainable rights economy on the Internet (Koda 2020). On the other hand, the opponents of article 17 , such as the affected digital platforms, academics, lawyers and civil rights societies, argue that the law imposes extreme restrictions on the open Internet. They worry that the vagueness of the directive forces the platforms to implement strict upload filters to comply with article 17, which can challenge the users' right to freedom of expression. Furthermore, the critics argue that the means surpass the goal of fair remuneration for rightsholders (Cerf et al. 2018). In this sense, the actors have different expectations of article 17's implications to the industry.

\footnotetext{
*E-mail: fr.juul.jensen@gmail.com
} 
Through a study into article 17's implementation in Denmark, this paper investigates the ways in which article 17 will affect the innovation processes in the European music industry. The aim is to uncover the multifaceted relations the actors find themselves in and shed light on the complex role human involvement, power dynamics, and internal and external forces have in innovation processes.

\section{Literature Review}

\subsection{Understanding the Role of Technology and Innovation in the Music Industry}

In many creative industries, such as the music industry, copyright is a vital factor, and the concept lies at the centre of their business models (Frith \& Marshall 2009). Although the digital disruption of the music industry seems like a unique event, the recording industry has cyclically been challenged by new technologies, which they considered to be a threat to the protection of their copyright and connected income streams. One of the earliest examples was the perceived threat of the radio because it was free to listen to, and the threat of 'home taping' in the 1970s was accused of 'killing music' (Frith 2001 in Rogers \& Preston 2016).

In these early examples, the consumer electric sector was the most powerful sectoral force that shaped how music and culture are mediated and experienced. However, Hesmondhalgh and Meier (2018) identify a shift in the twenty-first century, where the information technology sector has taken the consumer electric sector's role as the leading force in driving the technological change in the industry.

With the digitalisation of the music industry, the actors found themselves in a situation where the current legislation reportedly was no longer applicable. When the e-commerce directive was put into effect, it did not foresee the changing business models and user behaviours that would come years later. Currently, the industry identifies the platforms with user-uploaded content, and the business models around them, as the biggest among threats having the potential to undermine the industry's economics. One example of such a platform is Google's YouTube, which provides access to an enormous amount of content, most of it uploaded by the users themselves. YouTube has been described as a platform that has tested the boundaries of copyright infringement (Hesmondhalgh \& Meier 2018). At the same time, social media platforms such as Facebook and Instagram have also evolved into hosting copyright-infringing content through user-uploads in the forms of, for example, music and movies (Nordgård 2018).

The involvement of the external industries has changed, as the IT sector looks to exploit music consumption to support their core businesses instead of profiting off the commercial rights to the music recordings like the consumer electronic sector. Nordgård (2018, p. 6) explains how tech companies such as Apple, YouTube and Spotify "are driven to engage with music companies in order to gain access to recorded content, rather than to integrate with labels and publishers in the manner suggested by claims about convergence and (horizontal or vertical) integration". In that sense, the tech companies see music as a valuable digital artefact but do not seek industrial opportunities in music production.

As the IT sector is not interested in participating in the market of recorded music, it appears that the current actors in the recording industry are not threatened on their existence, although their current business models are challenged. In fact, the internal power structures within the industry remain intact, with only a few major labels controlling the industry, and the wealth continues to be highly concentrated (Rogers \& Preston 2016). The history of the music industry seems to indicate that the industry incumbents have repeatedly managed to reorganise themselves to respond to perceived threats and so-called value gap issues. In many cases, they consolidated their power simultaneously.

\subsection{Article 17 - Closing 'The Value Gap'}

Rightsholders have for a long time argued that there exists a so-called 'value gap', which portrays the opinion that online content-sharing platforms derive unreasonable value from providing the possibility for users to upload and access copyright-protected works without obtaining prior permission or license from the underlying rightsholders (Goossens 2019). In the legislation prevailing before article 17, these platforms could use the so-called 'hosting exemption' provided by article 14 (European Parliament, Council of the European Union 2000). The hosting exemption allowed them to avoid liability from the content their users upload as long as they are unaware of the illegal content and remove it when receiving knowledge about it (Goossens 2019).

The European Parliament's new copyright directive for the digital single market targets a broad range of copyright uses online. The substantial updates to the existing copyright law are expected to significantly impact how content is created, exploited and consumed online (Goossens 2019). Most relevant to this study is the directive's article 17, known as article 13 in previous proposals (before finalisation of the text), which creates a new group of 
online platforms, 'online content sharing service providers' (OCSSPs), to which this new article will pertain. The new definition targets the 'grey area' actors of digital platforms such as Youtube and social media platforms. The EU's intention with article 17 is to eliminate the legal uncertainty within which the platforms have functioned, now clearly stating that an agreement with rightsholders is necessary to host copyright-protected material on their online sharing platforms (Andersen 2019). It is, furthermore, a step to harmonise EU law applicable to copyright in the internal market. The rightsholders expect these terms to provide a stronger negotiation position, thereby filling the current perceived value gap between the parties (Koda 2020).

\subsection{The Role of Regulation and the Controversy of Article 17}

Regulations can erect or lower barriers to developing new technologies, but technology can also affect regulation, most often when new technologies make existing regulation obsolete (OECD, n.d.). Pelkmans and Renda (2014) have studied how specifically EU regulation tends to hinder or stimulate innovation. Their study finds that different types of regulatory approaches will impact innovation in different ways. If the rules of the market base themselves on rigid and prescriptive regulation, innovation processes can be hampered. In contrast, positive impacts on innovation processes can be achieved if compliance costs and administrative burdens are low (Pelkmans \& Renda 2014).

During its many years in the making, the directive, especially article 17 , has received much criticism. Some voices in the discussion call it the rescue of the music industry, while others believe it will destroy the Internet as we know it. In its mission of rebalancing the argued value gap, critics claim the law's consequences will 'break the internet' (Goossens 2019). Among both international and Danish scholars and lawyers, there exists considerable uncertainty about the legal effect of article 17 (Riis \& Schwemer 2018). The vagueness of the directive is one of the most criticised aspects, both from academics, lawyers, civil rights societies and the companies being affected. Owing to the vagueness, critics fear that the national regulation can differ significantly between the countries and ultimately result in the opposite of streamlining the internal market (Frederiksen 2019).

Critics, furthermore, argue that article 17 is trying to solve a specific problem in a specific business area while also trying to cover unknown future scenarios (Frederiksen 2019). The legislation is described as a considerable loss in the light of the overall purposes of making copyright adequately serve its function in the internal digital market and creating competitive conditions in Europe's culture industry (Frederiksen 2019).

\subsection{Political Engagements in the Industry}

The industry's engagement in political processes is complex and happens in overlapping layers. The opposing actors' political engagement and the vested interests connected to their arguments, for example those stated here in the paper, are therefore not necessarily visible at first hand to the public. The previously mentioned IT companies that have a stake in the music industry operate individually on a political level but are also organised in the European trade organisation DOT Europe (known as EDiMA until 2020), which has been very critical of article 17 in its communication (EDiMA 2019). Civil rights organisations, such as the IT-political association, operate independently in Denmark and are members of European Digital Rights (EDRi), an association of civil and human rights organisations across Europe. EDRi is a member of the SaveYourlnternet campaign that has been run as a critique of the implementation of article 17 (SaveYourInternet, n.d.). The rightsholders organised themselves around the campaign labelled \#EuropeForCreators, communicating the importance of fair remuneration on digital platforms (EuropeForCreators, n.d.). Furthermore, the rightsholders mobilised famous artists and songwriters to tell the public and politicians how important article 17 is in receiving fair remuneration on digital platforms (Roliggaard 2018). These campaigns have been used as a valuable tool to control information streams and affect public opinion, politicians and authorities. In that sense, both sides of the argument around article 17 have tried to steer the public conversation about the central issue of article 17 , as they all had vested interests in the outcome.

\section{Theoretical Framework}

The research project uses theory as a 'sensitising device' to interpret the situation through a specific worldview. This means that the theory in the paper is used to illuminate interesting perspectives rather than to prove the validity of a specific hypothesis. 


\subsection{Defining Innovation Processes}

This paper understands innovation as a nonlinear process, where the timing or exact outcome is impossible to predict. Inspired by Garud et al. (2016), the paper understands innovation as a process in itself, which cannot be managed by traditional actions, as the unfolding process consists of a complexity that goes beyond the individual actor's control.

\subsection{Advocacy Coalition Framework (ACF)}

To understand the role of technology in policy processes and the actors' complex relations, the paper uses the ACF, which was initially developed by Sabatier and Jenkins-Smith (1988), and iteratively improved in the following decades. 'At the end of the paper, the political insights produced by the ACF will be discussed within the context of innovation processes, and the degree to which the implementation of article 17 signals a paradigmatic shift in the industry's innovation process will be ascertained. The framework suggests that policymaking in modern societies entails such great complexity that participants, who aim to influence policies, organise in a 'policy subsystem' (Weible \& Sabatier 2011). The foundation stones of the ACF consist of three levels:

"(1) a macro-level assumption that most policymaking occurs among specialists within a policy subsystem but that their behaviour is affected by factors in the broader political and socio-economic system

(2) a micro-level 'model of the individual' that is drawn heavily from social psychology; and (3) a meso-level conviction that the best way to deal with the multiplicity of actors in a subsystem is to aggregate them into 'advocacy coalitions.' These foundations, in turn, affect our dependent variables, belief and policy change, through two critical paths: policy-oriented learning and external perturbations." (Weible \& Sabatier 2011, pp. 192, 193).

The scope of the research project's policy subsystem will be focusing on the strongest institutions that structure interaction in the geographical space of Denmark. In the analysis, the actors of the 'Danish article 17 policy subsystem' for music copyrights will be defined, consisting of a broad selection of actors concerned with the issue of article 17 in both the public and private sectors. A strength and weakness of the framework are that the ACF focuses on key actors of the subsystem. It provides a necessary overview of a complex topic, but it is also a risk of simplifying the issue. For example, Google and Facebook are not the only IT companies affected by article 17, but they are significantly more present in political discussions than smaller platforms. Moreover, a small minority of actors could identify with the beliefs of an opposite coalition, for example artists that are against the new copyright legislation. It is important to be aware that such nuances can disappear.

In the ACF, the beliefs of the actors play a substantial role. The framework assumes that the actors' worldview is shaped by their pre-existing beliefs, creating different perceptions of the same information.

Based on the actor's beliefs, the ACF supposes that participants in the policy subsystem search for allies, who hold similar policy core beliefs, to share resources with and develop complementary strategies. If they furthermore interact in a nontrivial degree of coordination, they form an advocacy coalition, working together to some degree to achieve similar policy objectives (Weible \& Sabatier 2011). Finally, through these advocacy coalitions, they aim to influence governmental decisions.

The ACF provides tools to qualitatively analyse the actors' beliefs through the interpretation of the collected documents. Interpreting and analysing the documents reveal the actors' opinions towards specific policy core beliefs set up in the project's analysis phase. Through the ACF, the paper can go beyond just identifying the competing sides of the political debate and interpreting the actors' underlying beliefs and how they construct their actions.

\subsection{Innovation Paradigms}

A paradigm is defined as "a set of shared beliefs about cause and effect relationships and standards of practice" (Kuhn 1962, p. 44). In a paradigmatic shift, revolutionary - or radical - innovations push the power balances and fundamentally change how an industry works.

Viewing the project's problem through the lens of paradigms will help understand the extent to which political intervention will affect the industry's innovation processes. The paper will find inspiration in Giannopoulos and Munro's (2019) Paradigmatic Model of Revolutionary Change, visualised in Figure 1. Although the model is rather general, it provides the researcher with a practical sense of direction when studying the role of policy changes in innovation landscapes. The model connects the elements of the ACF with the theory of paradigms, which will be used to evaluate the conflicting advocacy coalitions and their beliefs. These findings provide critical insights regarding the extent to which the implementation of article 17 is expected to affect the industry's innovation processes. 


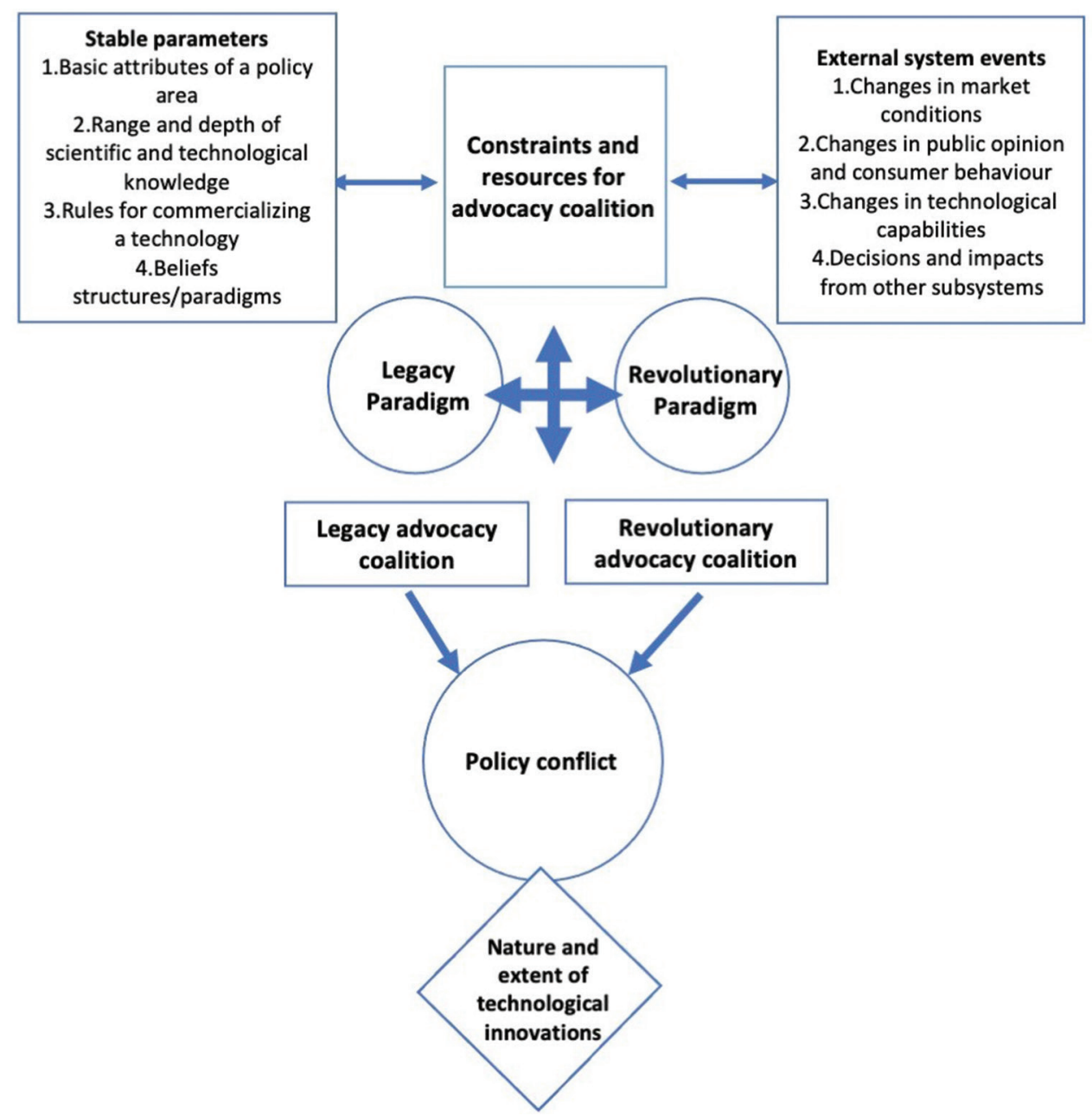

Figure 1. The paradigmatic model of revolutionary change by Giannopoulos and Munro (2019).

The model builds on top of the beliefs in the ACF, as it analyses cognitive factors to understand the effects of the opposing coalitions' behaviour in the industry. The analysis will uncover the members of the opposing advocacy coalitions and how their key beliefs in effect constitute different paradigms. These paradigms resemble the political forces that are for and against certain changes in the industry. In any revolutionary change, there will always exist a conflict between actors benefiting from the status quo and those that see advantages in significant technological and policy change. The stable parameters and external system events surrounding the Danish article 17 policy subsystem define the constraints and resources available to each coalition. Therefore, they will play a key role in determining how the power balances of the industry are being changed and altering the landscape in which the actors innovate. The findings will provide valuable insights when discussing whether these changes can be understood as constituting a new paradigm for the industry and ascertaining the extent to which such a paradigm constrains or fosters innovation.

\section{Methodological Framework}

\subsection{An Interpretive Research Project}

The paper aims to understand how the innovation processes in the digital industry might change because of the implementation of article 17. The paper conducts interpretive research on qualitative field data, following the principles of Klein and Myers (1999, p. 97) and Goldkuhl (2012, p. 138) to produce insights into the information systems 
phenomena of innovation processes in the digital music industry. This study aims to understand how the actors of the digital music industry, through their participation, construct certain realities. In connection with this, the interpretive approach assists in understanding the actors' perspectives of their realities and the roles they see themselves in.

\subsection{Data Collection}

The data collection process focused on finding documents that can provide a context for the research project through background information and historical insights. Connected with the choice of an interpretive research approach, the gathered documents will lay the foundation of gaining understanding and develop empirical knowledge (Bowen 2009). The documents gathered consist of books, newspaper articles, press releases, summaries and organisational reports. Prior academic literature has, furthermore, been collected to review the context of the study in academic literature. The literature search began with finding reviews and textbooks that could provide an overview of a specific corner of the project. Then, based on the information collected in the review papers and textbooks, the data collection iteratively looked to uncover the identified knowledge gaps in the already collected literature.

Totally 112 documents were qualitatively reviewed, and 36 were prioritised to become the primary empirical basis of the paper, based on their strong relevance. The documents are used to interpret the individuals' sense of reality, uncovering essential aspects in their agenda and understanding of their surroundings. Furthermore, the documents' insights are used to understand the roots of the issues raised in the paper.

\subsection{Data Analysis}

The collected documents were critically examined, and a strong focus was put on determining the documents' authenticity, credibility, accuracy and representativeness. Documents can have been produced with a specific agenda in mind, and it was essential to identify whom the information was supposed to target and why it was produced. During the search for literature and documents for the research project, gaps were identified in the available data. For example, documents concerning the music industry's implementation of the new copyright directive do not address the innovation processes of the industry. The majority of documents provided insights into the legal implications of the directive, and there was an apparent absence of the directive's implications on innovation processes, suggesting that this research project is addressing a gap.

Furthermore, in documents concerning how regulation affects innovation processes, no case studies focused on copyright industries. Many non-academic documents were incomplete in terms of addressing multiple perspectives on the issue, which in some cases suggests a deliberate focus on the issue from the author's side. However, connected with additional incomplete documents, which focus on other perspectives, gaps could be filled. The contrasting documents were then used to spark insights into the different understandings and agendas of the actors.

\section{Analysis}

\subsection{The ACF}

The literature review revealed how the majority of the actors were organised mainly into two political campaigns. The rightsholders campaigned to implement article 17 through the initiative EuropeForCreators, while the IT companies and the actors in the SaveYourlnternet campaign fought against the legislation. This suggests that the Danish article 17 policy subsystem comprises two primary advocacy coalitions, as presented in Table 1.

\subsubsection{Beliefs}

The Copyright coalition's deep core beliefs include prioritising copyright protection over technological developments and supporting regulation as a tool to achieve fair competition in a market. The Danish collective management organisation 'Koda' states:

\begin{tabular}{ll}
\hline Copyright coalition & IT coalition \\
\hline \hline $\begin{array}{l}\text { Music rightsholders: Record labels, music publishers, songwriters } \\
\text { and performers that identify with the Europe for Creators political } \\
\text { campaign (EuropeForCreators, n.d.) }\end{array}$ & $\begin{array}{l}\text { IT Companies, mainly Google and Facebook, and Civil Rights } \\
\text { Organisations, such as IT-Political Coalition, that identify with the Save Your } \\
\text { Internet political campaign (SaveYourlnternet, n.d.) }\end{array}$ \\
\hline
\end{tabular}

Table 1. Coalitions in the Danish article 17 subsystem. 
"Koda looks forward to article 17 being introduced into Danish legislation, creating a level playing field between digital music providers for the benefit of a sustainable rights economy on the Internet." (Koda 2020, n.p.).

In contrast, the IT coalition values technological developments more than the proper protection of copyrighted content and is worried that an excessively market can have unintentional consequences.

"As creators ourselves, we share the concern that there should be a fair distribution of revenues from the online use of copyright works that benefits creators, publishers, and platforms alike. But Article 13 is not the right way to achieve this. (...) The damage that this may do to the free and open Internet as we know it is hard to predict, but in our opinions could be substantial." (Cerf et al. 2018).

The IT coalition allegedly sympathises with the policy goal of the Copyright coalition, but they however believe that the avoidance of potential damage to the free and open Internet has a higher priority. Therefore, the core beliefs of the IT coalition prioritise accessibility of information and the Internet's flexibility over "fair distribution of revenues from the online use of copyright works" (Cerf et al. 2018, n.p.).

Based on the opinions uncovered in the literature review, the advocacy coalitions show different perspectives on the same issue. The Copyright coalition's preferred choice of policy instruments is regulation, which is shown in the case of article 17 and attempts to regulate the consumption of copyright content online at the beginning of the millennium (Nordgård 2018). Instead, the IT coalition prefers to see lawmakers creating incentives for the actors to follow a particular path but lets the market drive the innovation.

It indicates that the IT coalition believes the current distribution of liability between the uploader, platform and consumer is ideal and does not need modifications. Even though they discuss the same legislation, the coalitions have very different beliefs about what article 17 is primarily about. For the Copyright coalition, it is a matter of infringing copyrighted material that allows the wrong actors to benefit financially from the product (IFPI 2018a; Koda 2020). The IT coalition however primarily sees article 17 as an obstruction to free Internet, hindering both the public's access to information and new technological developments in their industry (Cerf et al. 2018). Table 2 summarises the advocacy coalitions' contrasting beliefs about article 17's central issue.

Interestingly, both coalitions believe their actions are in the best interest of the general public. The Copyright coalition believes the IT platforms currently exploit the liability of the users and wants to push the responsibility over on the platforms, as they are the ones profiting off it (IFPI 2018a). Article 17 is in that sense introduced to protect the public. On the other side, the IT coalition also claims they act in the general public's best interest because the implementation hinders them from expressing themselves freely and seeking new information (Kaye 2019).

\subsubsection{The impact of external factors}

The analysis of the policy subsystem uncovers the settings within their environment, but one of the focuses of the $\mathrm{ACF}$ is to understand how exogenous factors on a macro level greatly influence the dynamics within the internal subsystem. In this subsystem's case, exogenous factors on a macro level are relevant in both a geographical and sectoral perspective. While this paper studies the local Danish subsystem, it is most likely influenced by activities on the international, European level. The music industry is furthermore affected by changes and developments happening in external business sectors.

Weible and Sabatier (2011) describe the basic attributes of the problem area (or product) as a stable parameter that rarely changes. Therefore, it is not often the cause of behavioural or policy change within a policy subsystem. In this case, however, the basic attributes of the product have changed, and it has established new resources and

\begin{tabular}{|c|c|c|}
\hline Policy core belief & Copyright coalition & IT coalition \\
\hline Definition of the problem & $\begin{array}{l}\text { There exists a value gap that has to be } \\
\text { balanced. }\end{array}$ & $\begin{array}{l}\text { Regulating the Internet is complex and should be } \\
\text { kept at a minimum. }\end{array}$ \\
\hline The preferred choice of policy instruments & Regulation & Incentives \\
\hline Basic perspective on the Policy conflict & Copyright protection & Technological development \\
\hline Priority of which social group's interest & Rightsholders, general public & Innovators, general public \\
\hline $\begin{array}{l}\text { Can regulatory instruments solve problems in } \\
\text { the policy area }\end{array}$ & Yes & No \\
\hline
\end{tabular}

Table 2. Table of the advocacy coalitions contrasting beliefs. 
constraints for the subsystem actors to operate within. When the e-commerce directive was adopted, the product was still digital downloads, with attributes related to the analogue industry's physical sales. Within the last two decades, the value of music has evolved into a public good, which has made access to music ubiquitous and unpreventable (Nordgård 2018). This has changed one of the core premises of the previous legislation and the actors' behaviour, which influences the balance within the subsystem and its coalitions.

Controlling and curating access is a central component in the business model behind subscription-based streaming services such as Spotify. According to the IFPI, the services with this business model contribute to the Danish music industry's financial recovery. Streaming subscriptions was in 2018 accountable for $81.7 \%$ of the total revenue stream (including physical sales) in Danish record labels (IFPI 2018b). With the new business model, the industry has adapted to the new market conditions produced by the change in stable parameters. It is however the IFPI's opinion that the Danish market for recorded music still holds great untapped potential.

Platforms with user-uploaded content have managed to produce an alternative business model based on the new attributes of the product. In a sense, the critical question is still about accessibility, but instead of controlling access to the content, their business model provides access. This business model is however only accountable for a fragment of the rightsholders' revenue stream. For example, in $2018,29 \%$ of the total music streaming in Denmark happened on the YouTube platform. However, the platform is only responsible for $3.6 \%$ of the record labels' streaming revenues (IFPI 2018a).

From the perspective of the ACF, there seems to be a connection between these factors. The changed attributes of the product caused new market conditions, which produced the demand for new business models, where only some of them have been profitable for the members of the Copyright coalition. Their demand for updated regulation in the policy area is based on the change in the stable parameters.

\subsection{Innovation Paradigms}

The use of the Paradigmatic Model of Revolutionary Innovation by Giannopoulos and Munro (2019) builds further on the findings uncovered using the ACF. Suppose the implementation of article 17 represents significant changes to the current practices in the industry, as some actors argue it will, it should be possible to identify breaches in the dominating paradigm and belief system.

\subsubsection{A new paradigm}

The e-commerce directive governed the innovation landscape in the music industry for two decades, and as previously mentioned, it was implemented to provide an overall legal framework for online services in the internal market at a time where commerce on the Internet was still very new. The purpose was to remove obstacles and provide legal certainty to businesses and citizens, both in copyright-related industries and general commerce (European Parliament, Council of the European Union 2000). Therefore, the dominating paradigm of the last two decades is characterised by an innovation landscape that welcomes new technologies and solutions, as long as they follow the basic principles of the e-commerce directive. It becomes evident that the IT coalition benefited the most in that period, which means that those in the paradigmatic model enacted the dominating paradigm in this era.

With the assistance of the ACF analytical framework, the paper finds that the governmental institutions have changed beliefs since implementing the e-commerce directive, which has created the foundation of article 17. Therefore, this paper argues that the government should be understood as a previous supporter of the legacy innovation paradigm and the IT sector, prioritising the possibility of technological progress, rather than protecting the concept of copyright in its traditional form before digitalisation.

With the implementation of the new directive, and specifically article 17, the previous dominating paradigmatic belief system seems about to be contested. The deep core beliefs of the IT sector and the rightsholders are relatively unchanged. However, with article 17, the beliefs of the EU have changed, as identified in the advocacy coalition analysis. Article 17 seems to show a change in the belief system, now prioritising controlling certain dominating technologies and the companies behind them to protect both the rightsholders and the competing companies such as subscription-based streaming services. In contrast to the innovation landscape of the previous paradigm, the EU's change in beliefs indicates that they now look more critically upon technological developments. As a result, new technologies' underlying values and morals seem to have a more influential role. 
As the government, based on the decisions in the EU, decides the underlying framework of the innovation landscape, they keep their role in the new paradigm as a dominating actor. With their new beliefs, the members of the Copyright coalition now represent the dominating belief system and paradigm of the industry. The beliefs and practices of the IT coalition are therefore demoted to represent a competing paradigm.

\subsection{Policy Conflict in the Danish Article 17 Subsystem}

As shown in the visualisation below, the Copyright coalition now constitutes the 'Revolutionary Paradigm' as their beliefs dominate the policy subsystem. The new legislation has heavily constrained the IT coalition and brought political resources to the Copyright coalition. However, the terms 'Legacy Paradigm' and 'Revolutionary Paradigm', coined by Giannopoulos and Munro (2019), might not be the most appropriate in this case. 'Revolutionary' seems to refer to a radical innovation that fundamentally changes how an industry works. One could easily argue that although they return to constitute the dominating paradigm, the Copyright coalition's beliefs are in fact representing legacy beliefs (Figure 2).

The analysis found that the core beliefs of the coalition have not changed significantly for decades, and their reactions to previous historical examples of value gaps, such as home taping and online piracy, align with their response to the current perceived value gap. In a way, it can be argued that article 17 imposes legacy norms on the modern era. Therefore, the paper suggests describing the opposing belief systems differently; for example, such belief systems may be defined in terms of the Dominating and Subordinate Paradigm.

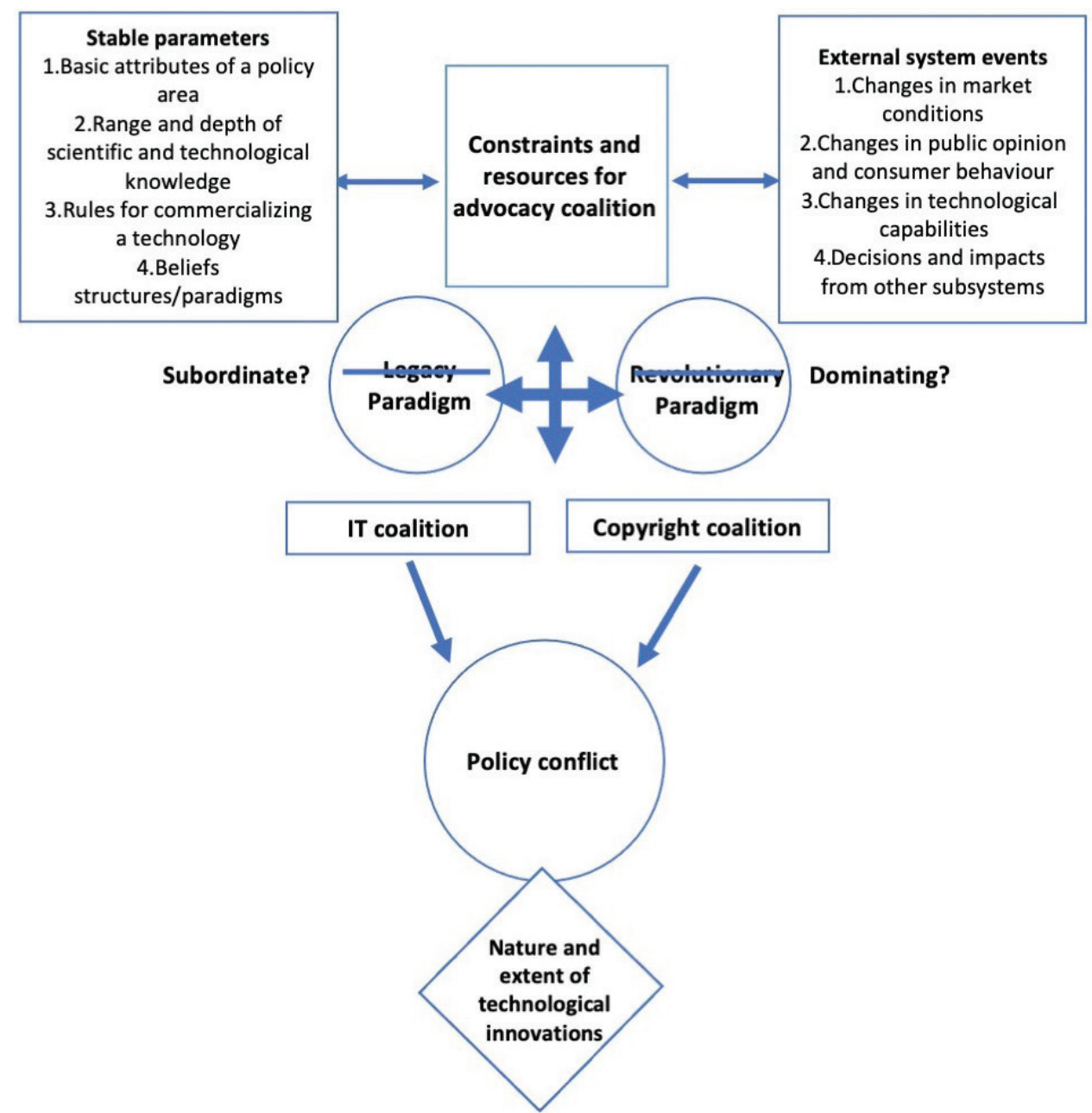

Figure 2. The Danish article 17 policy subsystem in The Paradigmatic Model of Revolutionary Change, inspired by Giannopoulos and Munro (2019). 


\section{Discussion}

The analysis reached the step of uncovering the policy conflict. It is, however, still unclear to what extent the new paradigm, and the implementation of article 17, will affect the innovation processes. The analysis uncovers several interesting issues that can indicate how the innovation landscape might change. The discussion thereby seeks to understand the last step of the model, which is the extent to which technological innovations will be affected by the factors found in the analysis.

\subsection{A Need for New Innovative Technologies?}

Although it is not explicitly mentioned in the final text of the directive, many voices expect that platforms will need very reliable filtering technology to fulfil the demands of article 17 - technology, which, according to Cerf et al. (2018), has not yet been developed. The algorithm will need to recognise music in its original recordings and modified versions, including samples, remixes, covers, and DJ mixes. The algorithm furthermore needs to have a sense of the context of the copyright use. The issue is especially challenging for smaller platforms without the same financial resources as the dominating industry actors such as Google and Facebook.

Concerns have been raised that there is a risk that the current, dominating platforms can increase their position in the market even further, as they are already building content recognition technologies and have the financial recourses to continue developing them (Frederiksen 2019). Owing to a paucity in resources, it is unlikely that smaller competitors will develop their own systems. Some anticipate that larger platforms, such as YouTube, can improve their market position through outcompeting smaller competitors merely by refusing to make their technology available to them. They can alternatively make their technology accessible to competitors for a specific price. A platform such as YouTube can thereby control many aspects of the market by making other platforms dependent on their technology.

Another scenario could be that article 17's demands will create innovative solutions that can be used to achieve compliance with the new legal framework. A market could rise for intermediaries that specialise in content matching and rights management services through filtering technologies. An example of such an intermediary is the company Pex, which, in its own words, is a global video and music search engine (Pex, n.d.). As an intermediary for multiple platforms, such entities can reach economies of scale and lower the high costs of compliance and heavy administrative burdens for the platforms, which, according to Pelkmans and Renda(2014), is one of the key obstructions to a thriving innovation environment. The platform can let Pex facilitate the copyright dispute resolution between the uploader and rightsholder, making the job easier for small platforms that are low in resources.

Interestingly, these innovations in copyright management would once again come from outside of the core music industry, which makes them highly dependent on a new set of IT actors that, to some degree, can determine the conditions of effective rights management.

\subsection{For how Long will Article 17 be Relevant?}

The vague formulation of article 17 is in part related to an effort to cover unknown scenarios in the future (Frederiksen 2019). From a historical perspective, it would be the first time legislation could cover unknown future scenarios in the music industry. The law's ability to cover future scenarios will be dependent on the revolutionary degree of the innovation. Article 17 might cover incremental innovations in the industry that do not change its underlying characteristics and business models or what the ACF describes as stable parameters. However, radical innovations are characterised by their ability to make existing regulations obsolete, and the industry has already experienced the difficulty of predicting the future. In the past instances, regulation has worked as a reactive measure, and it is therefore unlikely that the industry can expect regulation to have a proactive role in structuring the innovation processes of the industry.

Furthermore, the paper has outlined how exogenous companies and sectors have consequently introduced significant changes in the music industry. Although article 17 will influence the innovation process of what we understand as the music industry today, it will not affect the innovation processes happening outside of the industry, which might someday enter the industry. The rightsholders and the government should therefore not expect that the implementation of article 17 will be able to govern the future radical developments of the industry. 


\subsection{The Opportunities within Stronger Collaboration}

The policy issue of article 17, uncovered in this paper, might paint a picture of two coalitions unwilling to collaborate and needing the government as a mediator to settle their disputes. This is however not the whole picture. Their relationship proves to be significantly more complex. Even though the members of each coalition have been publicly criticising each other for more than a decade, they have still worked together on several projects. For instance, the record labels and publishers already have a licensing deal with YouTube, although they seek to increase their remuneration with article 17 (Dredge 2019). They furthermore already have access to monetise or takedown copyright-infringing content through YouTube's monitoring tool, Content ID (Youtube, n.d.). All the major record labels and publishers have licensed Facebook to use music in user-uploaded videos on their platforms (Deahl 2018). Even more interesting is that YouTube launched YouTube Music in 2018; this is their subscription-based streaming platform that, being a service containing licensed music only, directly competes with services such as Spotify and Apple Music (Deahl 2018). Their ability to collaborate is therefore evident, although they use public communication to increase their political influences. The paper acknowledges that governmental interference is at times the only solution, but its slow response time shows that it should be used as a last resort. The rightsholders' reliance on new regulations as the tool to increase their role in the industry makes them unable to react to changes when they emerge.

Considering that the IT coalition lost its dominating paradigm, it can be argued that they might have exploited their position too much. While the IT companies and platforms might have thrived during the previous paradigm, the new legislation might not have been as strict if the two coalitions had found a middle ground earlier. Governmental intervention is therefore not the most effective tool to reach a new wanted destination for any of the coalitions. Furthermore, the Copyright coalition should learn from the IT coalition's experiences of constructing the dominating paradigm. Excessively dominant conduct in the industry is not necessarily the best decision for the long term. A new, long term collaboration between the coalitions will only last if all parties find value in the cooperation.

With the rightsholders' increased negotiation power based on article 17, they may be able to dominate their relationship with the members of the IT coalition. However, if they seek influence in the long term, it is necessary that the coalitions find the relationship mutually beneficial. If the IT coalition does not sense their value in the collaboration, they might seek to control the situation in other ways, feasibly through innovations meant to decrease the rightsholders' control. Furthermore, if the rightsholders lose the support from the legislators in the EU and locally in Denmark, they risk going back to be the competing paradigm. The resources available to the Copyright coalition can change if the implementation of article 17 results in damaging free and open Internet, which is a likely outcome according to the IT Coalition's argument. If the users' consumption patterns are significantly restricted, the public opinion could change, putting intense pressure on the elected politicians.

\subsection{Facilitating Greater Collaboration}

Owing to the coalitions' current self-perceptions and beliefs, the hybrid industry of music and IT, where one can consider the two parties in the same industry, has yet to be developed. The findings of both previous research and this paper show that the majority of technology disruptions and business models, which the music industry has experienced, have started outside of the industry. It indicates that they are heavily interdependent with external sectors. If the rightsholders manage to adjust their self-perception and balance between copyright protection and copyright exploitation, they are in a stronger position to coorporate with start-ups early on. A change in beliefs would allow restructuring in their organisations. Opening their organisations could provide powerful and creative sources to new ideas, services and technologies in development outside of their industry. Such actions could likely improve the collaboration with the next large actors of external sectors, which would minimise the polarity they experience with the current leading actors in the IT sector.

Fortunately, some initiatives have started to rise. For example, the goal of the new 'Music Tech Europe Academy', co-funded by the Creative Europe Programme of the European Union, is reportedly to "further develop the music tech ecosystem in Europe and create a level playing field between tech-savvy entrepreneurs, artists, music industry players and investors, to allow joint innovation efforts for the future music sector" (musictecheuropeacademy, n.d.). These joint innovation efforts could help connect the music industry with a new IT actor earlier in the process, instead of when an IT platform has already scaled significantly, and the two are forced to collaborate. Interestingly, the governmental body is funding such activities, which could indicate that they too are looking to change the current structures, where legislation very late in the process often needs 
to reset or adjust market conditions for the involved actors. The initiative furthermore acknowledges, alongside this paper, that "[a] substantial and growing part of the innovations in the music sector takes place outside the traditional music industry and most of the change came and will continue to be coming from the bottom up" (musictecheuropeacademy, n.d.). If the actors of the Copyright coalition would increase their acceptance of this fact and consider external innovation as more of a feature than a threat, the paper believes they would stand in a much stronger position to tackle new disruptions going forward.

\subsection{How will the Innovation Processes be Changed?}

With article 17, the rightsholders expect to increase their power in negotiations with platforms, as the EU's shift in beliefs has significantly increased the consequences for copyright infringement. This looks to become the case, but it is worth discussing how much there is to win. Rightsholders will increase their revenue on user-uploaded content platforms, but what remains to be discovered is if the large IT companies will concentrate their power within the industry and make the rightsholders even more dependent on their technologies. If the current dominating platforms manage to concentrate their position in the industry, it will likely be increasingly difficult for the rightsholders to find alternative distribution channels to deliver their product to their consumers. The stronger market concentration will raise the entry barriers for new competitors, increasing the rightsholders' already strong dependence on these companies. Innovation processes within the industry can therefore stagnate, making the industry environment more static.

When discussing in what ways the innovation processes of the industry will change, it is also essential to raise the question of what the changes mean. Is a stagnating innovation environment positive or negative? Opinions on this matter might very well be relative. If innovations slow down, the consumer will not need to adjust to new consumption possibilities continually. However, most innovations enhance the value for the consumer, which means that a more static market would most likely not be in the consumer's interest.

Stagnation in the amount of new and improved technologies does not, however, seem to worry the rightsholders. When looking at their somewhat historical passive role in technology developments and demands for updated regulations, they seem to be focused on increasing their control of the status quo. The paper's findings indicate that the rightsholders are not necessarily looking for a vibrant innovation environment in the industry. However, the consequence is that they have found themselves in a position where there has been a constant need to catch up. Moreover, by the time they caught up, the market was already starting to move in new directions. Therefore, the rightsholders might find themselves in the same position again within the next 5-10 years if the market continues to develop at the same pace as now.

Based on the historical events, regulatory measures seem to be characterised by their delay in connection to the market's developments. It is doubtful if the rightsholders' strategy of using regulation as their prioritised tool will ever allow them to follow continuous changes in the market and industry experience. If the Copyright coalition attempts to control and decrease the innovation processes of the industry, the risk of a paradigmatic shift will be higher, as innovations pose a more significant threat to the dominating belief system. If the rightsholders were to utilise their new negotiation power to build closer collaboration with the members of the IT coalition, they could take part in the continuous developments of the industry. It would decrease their risk of once again falling behind the industry's technological developments and reduce the need for the government's time-consuming interference aimed at reinstituting the balance in the industry.

\section{Conclusion}

Through a study into article 17's implementation in Denmark, this paper has explored the ways in which article 17 will affect the innovation processes in the European music industry. Based on the method of document analysis, the paper has uncovered the complexity and uncertainty the industry experiences with the new legislative measures of article 17.

Through the ACF, the paper studied the cognitive factors of the actors and uncovered the exogenous factors influencing the course of the restructuring of the industry and its innovation landscape. The ACF's theoretical assumptions and conceptual lenses have illuminated policy making's strong influence on the Danish digital music industry's practices, and their analysis by this paper has resulted in the following findings: Since the implementation of the e-commerce directive in 2001, the basic attributes of the industry's product have changed, which has 
established new resources and constraints for the subsystem actors to operate within. The value of music has evolved into a public good, which has made access to music ubiquitous and unpreventable. The business model of paid music streaming subscriptions became popular, but platforms with user-uploaded content unexpectedly produced an alternative business model without costs for the consumer. The rightsholders argue that the business model holds a value gap, which motivated them to seek governmental intervention in the market. Unintentional outcomes of previous legislation have made the EU reconsider their approach to regulating business practices in the digital space to protect both consumers and competitors. These factors have been the primary catalysts for the restructuring of the industry.

Building upon the findings uncovered using the ACF, the paper used the tools of the Paradigmatic Model of Revolutionary Innovation to determine the degree to which the implementation of article 17 signals a paradigmatic shift in the industry's innovation process. Based on this model, the paper identifies that the restructuring of the industry's actors affects the innovation landscape. The implementation of the new directive, specifically article 17 , contests the industry's previous dominating paradigmatic belief system. The rightsholders now represent the dominating belief system and paradigm of the industry. The paper's use of the theoretical concepts of advocacy coalitions and innovation paradigms has not entirely determined the extent to which the new paradigm will affect the innovation processes. They have, however, revealed several interesting issues that can indicate how the innovation landscape might change.

With article 17, the rightsholders expect to increase their power in negotiations with platforms, as the EU's shift in beliefs has significantly increased the consequences for copyright infringement. Rightsholders seek to increase their revenue on user-uploaded content platforms, but what remains uncertain is whether the large IT companies manage to concentrate their power, which will raise the entry barriers for new competitors, in turn increasing the rightsholders' already strong dependence on these companies.

If the rightsholders attempt to control and decrease the innovation processes of the industry, the risk of another paradigmatic shift will be higher, as innovations would pose a more significant threat to the dominating belief system. In contrast, if they seek involvement in a dynamic innovation landscape and increasingly acknowledge interdependencies with external sectors, the issue will likely be reduced. As a result, innovations would be a smaller threat to the paradigm, as the dominating members incrementally adjust the belief system to fit the evolving industry.

The ways in which the industry's innovation processes will change are codetermined by the role the rightsholders choose to take on in the future. If they wish to maintain their stronger position in the industry, their new, more influential negotiation role can be used as a springboard to secure codetermination in the innovation landscape moving forward and thereby decrease the risk of once again falling behind the technological developments of their surroundings.

\section{Biographical note - Frederik Juul Jensen}

Frederik graduated in June 2020 from the IT University of Copenhagen with a master's degree in Digital Innovation and Management. He has a bachelor's degree in Music Management from the Rhythmic Music Conservatory in Copenhagen. Simultaneously with his studies, Frederik has worked within different fields of the Danish and international music industry, and is currently working as an artist manager fulltime.

\section{References}

Andersen, L. S. (2019) Kontroversiel copyright-lovgivning nærmer sig målstregen, Information, Available at: https:// www.information.dk/indland/2019/02/kontroversiel-copyright-lovgivning-naermer-maalstregen (13 April 2020).

Bowen, G. A. (2009) "Document Analysis as a Qualitative Research Method", Qualitative Research Journal, vol. 9, pp. 27-40. https://doi.org/10.3316/QRJ0902027.

Cerf, V., Berners-Lee, T., Esterhuysen, A. \& Kahle, B. (2018) Article 13 of the EU Copyright Directive Threatens the Internet, Available at: https://www.eff.org/files/2018/06/12/article13letter.pdf (13 April 2020).

Deahl, D. (2018) YouTube Music and YouTube Premium officially launch in US, Canada, UK, and other countries 25, The Verge. Available at: https://www.theverge.com/2018/6/18/17475122/youtube-music-premium-launchus-canada-uk (10 May 2020). 
Dredge, S. (2019) Lickd Boss Says Article 13 Issue 'is not Going to Go Away,' Musically, Available at: https:// musically.com/2019/04/15/lickd-boss-says-article-13-issue-is-not-going-to-go-away/ (7 May 20).

EDiMA (2019) EDiMA reaction: EU Copyright Directive is not fit for digital era, Available at: https://edima-eu.org/ news/edima-reaction-eu-copyright-directive-is-not-fit-for-digital-era/ (6 May 2020).

European Parliament, Council of the European Union (2000) Directive 2000/31/EC, Official Journal of the European Union.

EuropeForCreators (n.d.) Europ For Creators - About Us. Eur. Creat. Available at: https://www.article13.org/ about-us (7 May 20).

Frederiksen, R. B. (2019) Ophavsretsforsker om EU-direktiv: Svært at forudsige konsekvenserne. Version 2. Available at: https://www.version2.dk/artikel/ophavsretsforsker-eu-direktiv-svaert-at-forudsige-konsekvenserne-1087590 (13 April 20).

Frith, S. \& Marshall, L. (eds.) (2009) Music and Copyright, 2nd Edn., transferred to digital print. ed. Edinburgh University Press, Edinburgh.

Garud, R., Gehman, J., Kumaraswamy, A. \& Tuertscher, P. (2016) "From the Process of Innovation to Innovation as Process", in The SAGE Handbook of Process Organization Studies. SAGE Publications Ltd., London, EC1Y 1SP, pp. 451-465. https://doi.org/10.4135/9781473957954.n28.

Giannopoulos, G. A. \& Munro, J. F. (2019) "Innovation Ecosystems - A Systems-Based Theory of Innovation", in The Accelerating Transport Innovation Revolution, Elsevier, pp. 19-41. https://doi.org/10.1016/B978-0-12813804-5.00002-4.

Goldkuhl, G. (2012) Pragmatism vs Interpretivism in Qualitative Information Systems Research, European Journal of Information Systems, vol. 21, pp. 135-146. https://doi.org/10.1057/ejis.2011.54.

Goossens, S. (2019) Article 13 (now Article 17) of the New EU Copyright Directive: What You Need to Know. Reed Smith Client Alerts. URL https://www.reedsmith.com/en/perspectives/2019/04/article-13-now-article-17-of-thenew-eu-copyright-directive (accessed 3.15.20).

Hesmondhalgh, D. \& Meier, L. M. (2018) "What the Digitalisation of Music Tells us about Capitalism, Culture and the Power of the Information Technology Sector", Information, Communication \& Society, vol. 21, pp. 1555-1570. https://doi.org/10.1080/1369118X.2017.1340498.

IFPI (2018a) Åbent brev til de danske medlemmer af Europa-Parlamentet. Available at: http://www.ifpi.dk/abentbrev-til-danske-medlemmer-af-europa-parlamentet (1 September 2021)

IFPI (2018b) MUSIK SELSKABER 2018. Available at: http://www.ifpi.dk/publikationerne (10 August 2021)

Kaye, D. (2019) EU Must Align Copyright Reform with International Human Rights Standards, Says Expert, OHCHR, Available at: https://www.ohchr.org/EN/NewsEvents/Pages/DisplayNews.aspx?NewsID=24298\&LangID=E (6 May 2020).

Klein, H. K. \& Myers, M. D. (1999) "A Set of Principles for Conducting and Evaluating Interpretive Field Studies in Information Systems", Management Information Systems Quarterly, vol. 23, p. 67. https://doi.org/10.2307/249410.

Koda (2020) Det mener Koda om artikel 17 og ophavsretsdirektivet. Koda. Available at: https://www.koda.dk/omkoda/nyheder/det-mener-koda-om-ophavsretsdirektivet-og-artikel-17.

Kuhn, T. S. (1962) The Structure of Scientific Revolutions, University of Chicago Press, Chicago, IL.

musictecheuropeacademy (n.d.) Music Tech Europe Academy. Available at: https://www.musictecheuropeacademy. eu/ (1 September 2021).

Nordgård, D. (2018) The Music Business and Digital Impacts: Innovations and Disruptions in the Music Industries, Music Business Research. Springer International Publishing, Cham. https://doi.org/10.1007/978-3-31991887-7.

OECD (n.d.) Regulatory Reform and Innovation. OECD. Available at: https://www.oecd.org/sti/inno/2102514.pdf (18 April 2020).

Pelkmans, J. \& Renda, A. (2014). "Does EU regulation hinder or stimulate innovation?", Centre for European Policy Studies, Brussels. ISBN 978-94-6138-427-0

Pex (n.d.) Attribution Engine. Pex. Available at: https://pex.com/how-it-works/ (17 May 2020).

Riis, T. \& Schwemer, S. F. (2018) "Leaving the European Safe Harbor, Sailing Towards Algorithmic Content Regulation", SSRN Electron Journal, https://doi.org/10.2139/ssrn.3300159.

Rogers, J. \& Preston, P. (2016) "Crisis and Creative Destruction: New Modes of Appropriation in the Twenty-First Century Music Industry", in Business Innovation and Disruption in the Music Industry. Edward Elgar Publishing, pp. 53-72. https://doi.org/10.4337/9781783478156.00009. 
Roliggaard, S. (2018). "Thomas Helmig, Marie Key, Medina og flere til EU- parlamentarikere: Husk at stemme ja til ny lov om ophavsret på torsdag". Available at: https://politiken.dk/kultur/musik/art6612616/Husk-at-stemmeja-til-ny-lov-om-ophavsret-på-torsdag (10 May 2020)

Sabatier, P. A. \& Jenkins-Smith, H. (1988) "An Advocacy Coalition Model of Policy Change and the Role of Policy Orientated Learning Therein", Policy Sciences, vol. 21, pp. 129-168.

SaveYourInternet (n.d.) Save the Internet Website. Available at: https://saveyourinternet.eu (7 May 2020).

Weible, C. M. \& Sabatier, P. A. (2011) "Advocacy Coalition Framework", in: International Encyclopedia of Political Science. SAGE Publications, Inc., Thousand Oaks, CA, US. https://doi.org/10.4135/9781412959636.n7.

Wikström, P. \& DeFillippi, B. (eds.), (2016) Business Innovation and Disruption in the Music Industry. Edward Elgar Publishing, Northampton, MA.

Youtube (n.d.) Content ID Overview. Youtube. Available at: https://creatoracademy.youtube.com/page/lesson/ respond-to-content-id-claims_content-id-claims-overview_video?cid=respond-to-content-id-claims\&hl=en (18 May 2020). 